\title{
Diagnóstico por imagem no trauma raquimedular - princípios gerais
}

\section{Diagnostic imaging in spinal cord trauma - general principles}

\author{
Marcelo Bordalo Rodrigues
}

Rodrigues MB. Diagnóstico por imagem no trauma raquimedular - princípios gerais / Diagnostic imaging in spinal cord trauma - general principles. Rev Med (São Paulo). 2011 out.-dez.;90(4):174-82.

RESUMO: O conhecimento dos mecanismos fisiopatológicos no trauma raquimedular é importante para o entendimento das características das diversas lesões. Os métodos por imagem são essenciais no seu diagnóstico e estadiamento, devendo-se, no entanto, sempre ser correlacionados com o quadro clínico para adequada valorização dos achados por imagem e conseqüente conduta terapêutica.

DESCRITORES: Diagnóstico por imagem; Traumatismos da coluna vertebral/fisiopatologia; Traumatismos da coluna vertebral/radiografia; Traumatismos da medula espinhal/fisiopatologia; Traumatismos da medula espinhal/radiografia; Ferimentos e lesões/radiografia.
ABSTRACT: The knowledge of the pathophysiological mechanisms in spinal trauma is important to understand the characteristics of the several injuries. Imaging methods are essential in diagnosis and staging, which should always be correlated with clinical findings in order to make appropriate imaging interpretation and adequate treatment.

KEYWORDS: Imaging diagnostic; Spinal cord/physiopathology; Spinal cord/radiography; Spinal cord injuries/physiopathology; Spinal cord/radiography; Wounds and injuries/radiography.

Medico Coordenador do Serviço de Radiologia do Instituto de Ortopedia e Traumatologia (IOT) do HCFMSUP. Médico Responsável pela Radiologia Músculo-esquelética do Instituto de Radiologia (InRad) do HCFMUSP.

Endereço para correspondência: Marcelo B. Rodrigues. InRad-HCFMUSP. Av. Dr. Eneas de Carvalho Aguiar, $255-3^{\circ}$ andar. Cerqueira César. São Paulo, SP. CEP: 05403-001. E-mail: marcelo.bordalo@ hc.fm.usp.br 


\section{INTRODUÇÃO}

$\mathrm{O}$ trauma na coluna vertebral e na medula espinhal vem aumentando nos últimos anos em decorrência do aumento nos acidentes de trânsito. Existem três localizações mais freqüentes de trauma na coluna vertebral: C1-C2, C5-C7 e T12-L2 1,2. Em crianças menores que 12 anos, existe uma maior incidência de lesões em C1, C2 e na articulação atlanto-axial.

As lesões da medula espinhal ocorrem em cerca de 10 a $15 \%$ das fraturas e deslocamentos ${ }^{3}$. As lesões da coluna cervical levam a dano neurológico em cerca de $40 \%$ dos $\operatorname{casos}^{4}$, ao contrario das lesões nas colunas torácica e lombar que levam a lesões neurológicas em, respectivamente, $10 \%$ e $4 \%$ dos casos. Se o paciente apresentar fratura envolvendo o corpo vertebral e os elementos posteriores com desalinhamento, a chance de dano neurológico sobe para $60 \%$.

Em geral, as lesões neurológicas ocorrem imediatamente após o trauma, mas podem ocorrer tardiamente. Outro dado importante é que, em cerca de $10 \%$ dos casos de lesão medular pós-traumática, não há alterações ao raio- $X$ simples $(R X)^{5,6}$. Estes casos são mais freqüentes em pacientes idosos que apresentaram uma lesão em hiperextensão.

\section{MECANISMO DE LESÃO}

As lesões pós-traumáticas da coluna vertebral são, em geral, resultantes de forças indiretas levando a um movimento exagerado, tais como: flexão, extensão, rotação, compressão axial (vertical), distração, cisalhamento e afastamento (Figuras 1 a 4).

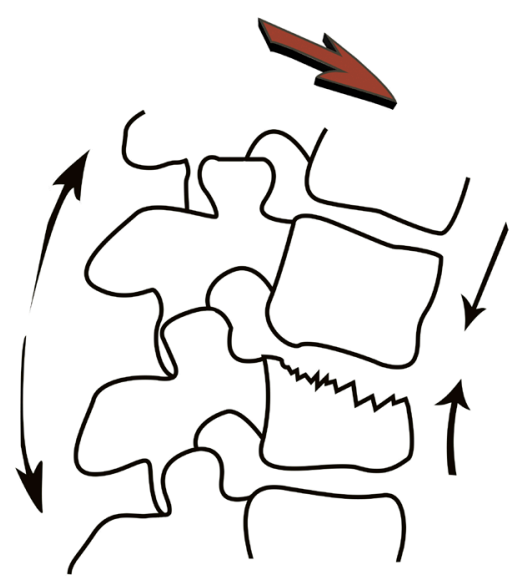

Figura 1. Lesão por hiperflexão da coluna. Esquema demonstra hiperflexão da coluna com fratura compressiva do platô superior e acunhamento vertebral

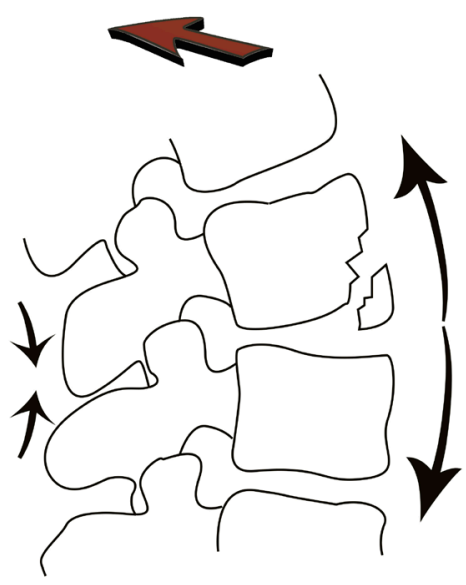

Figura 2. Lesão por hiperextensão da coluna. Esquema demonstra hiperextensão da coluna com fratura do platô ântero-inferior e formação de um pequeno fragmento ósseo triangular

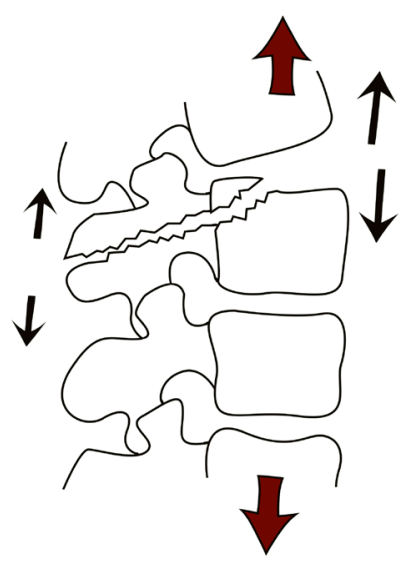

Figura 3. Lesão por distração da coluna. Esquema demonstra distração da coluna com fratura horizontal dos elementos posteriores, podendo se estender para o corpo vertebral

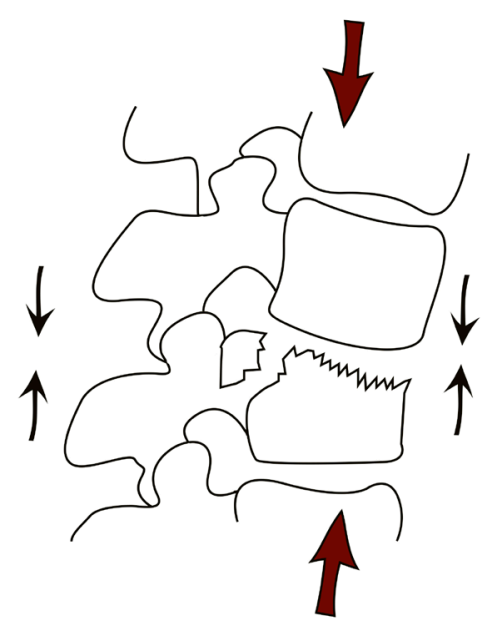

Figura 4. Lesão por compressão axial da coluna. Esquema demonstra compressão axial da coluna com fratura compressiva e acunhamento vertebral, com retropulsão de fragmento ósseo 
A estabilidade da coluna vertebral é mantida pela interação entre os corpos vertebrais, ligamentos, articulações interapofisárias e discos intervertebrais (Figura 5). A presença e o grau de instabilidade dependem da extensão da lesão e da característica das estruturas intactas.

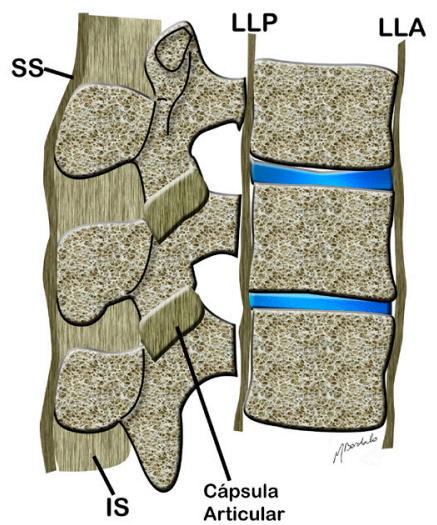

Figura 5. Anatomia ligamentar da coluna. Esquema demonstra estruturas ligamentares que auxiliam na estabilidade da coluna. LLA- Ligamento longitudinal anterior. LLP - Ligamento longitudinal posterior. IS - Ligamento Interespinhoso. SS- Ligamento Supraespinhoso. Cápsula Articular - Complexo cápsulo ligamentar da articulação interapofisária

O conceito de estabilidade vertebral das três colunas, criado por Denis ${ }^{7,8}$ é útil no entendimento da biomecânica das lesões, auxiliando no diagnóstico e, consequentemente, no tratamento. De acordo com esta teoria, a coluna vertebral é dividida em três colunas: anterior, media e posterior (Figura 6). A coluna anterior consiste no ligamento longitudinal anterior, ânulo fibroso anterior e porção anterior do corpo vertebral. A coluna media consiste no ligamento longitudinal posterior, no ânulo fibroso posterior e porção posterior do corpo vertebral. A coluna posterior consiste no arco neural e partes moles ao seu redor. Conceitualmente a coluna anterior é separada da posterior através da coluna media, que funciona como uma "dobradiça" durante a flexo-extensão. Em geral, as lesões vertebrais na qual a coluna media permanece intacta são estáveis e aquelas na qual ela está lesada são instáveis.

Devido as diferentes características mecânicas e de mobilidade, a classificação de lesão vertebral deve ser separada em três regiões anatômicas: região atlanto-axial (côndilos occipitais, C1 e C2), coluna cervical (C3 a C7) e coluna tóraco-lombar.

Esta classificação de lesão vertebral baseada no mecanismo patológico e localização está exemplificada na Tabela 1.

\section{COLUNAS}

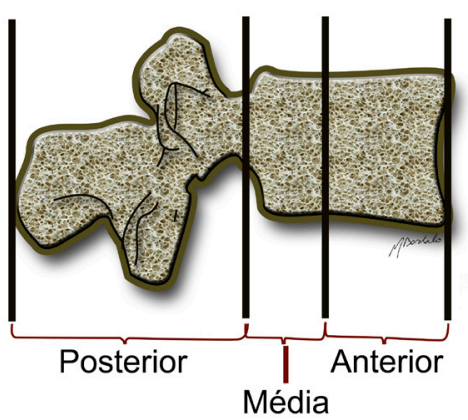

Figura 6. Teoria das 3 colunas. Biomecanicamente, a coluna é dividida em 3 partes: colunas anterior, média e posterior. A coluna média funciona como um "fulcro"ou "pivô" entre as colunas anterior e posterior. Quando há lesão da coluna média, a fratura é considerada instável e quando não há lesão da coluna media, é considerada estável. São consideradas componentes da coluna media o ligamento longitudinal posterior, o anel fibroso posterior e a porção posterior do corpo vertebral

Tabela 1. Classificação fisiopatológica do trauma da coluna cervical

\section{Flexão} Atlantoaxial

Coluna Cervical

Fratura do odontóide

Fratura da massa lateral de $\mathrm{C} 1$ ou $\mathrm{C} 2$

Fratura por compressão

\section{Extensão}

Atlanto-axial

Fratura do arco neural de $\mathrm{C} 1$

Fratura do arco anterior de $\mathrm{C} 1$

Fratura do enforcado

Fratura do odontóide

Fratura em lágrima de $\mathrm{C} 2$

Coluna Cervical

Lesão por hiperextensão

Fratura do istmo

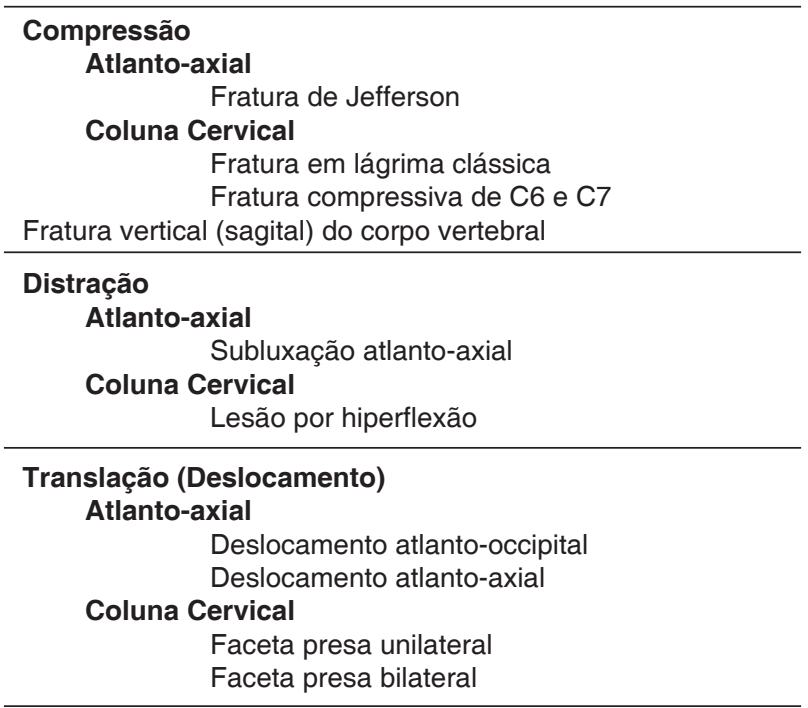




\section{DIAGNÓSTICO POR IMAGEM}

O papel dos métodos por imagem no trauma raquimedular é diagnosticar a fratura e/ou deslocamento e definir se é instável ou não.

\section{Radiografia simples}

A radiografia simples ou Raio-X $(R X)$ é considerada a técnica de escolha para a avaliação inicial do trauma raquimedular. Deve ser realizada levando-se em consideração os sinais clínicos do paciente. Se houver lesão de múltiplos órgãos ou déficit neurológico associados, as incidências realizadas são ântero-posterior (AP) e perfil que devem ser complementadas por uma tomografia computadorizada ou ressonância magnética. Se não houver sinais localizatórios, podem ser necessárias ainda outras incidências, como as oblíquas, para melhor identificar uma possível fratura/deslocamento.

A incidência em perfil deve, necessariamente, incluir todas as sete vértebras cervicais. As vértebras cervicais baixas podem não ser visibilizadas devido a sobreposição dos ombros. Isto pode ser atenuado puxando-se os braços para baixo. Se mesmo assim as vértebras não forem visibilizadas, pode se realizar a incidência do nadador, na qual um dos braços é extendido sobre a cabeça e o outro permanece ao lado do corpo (Figura 7). Nesta posição, o corpo fica em uma projeção oblíqua, permitindo a visibilização da transição cérvico-torácica. Na falha de visibilização com esta incidência, uma tomografia computadorizada é indicada.
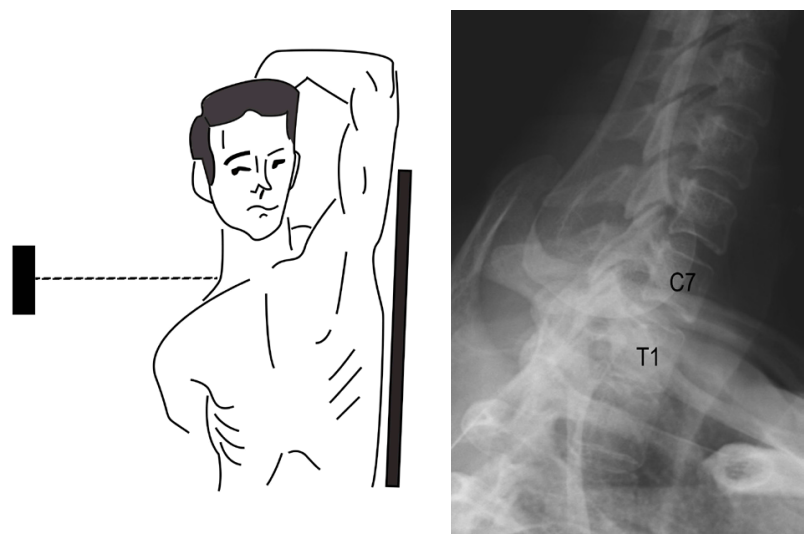

Figura 7. Incidência do nadador. (A) Esquema demonstrando posicionamento do paciente para obtenção da incidência do nadador. (B) Radiografia simples obtida com o posicionamento do nadador. Esta incidência é realizada para uma melhor visibilização da transição cérvico-torácica (C7 e T1)

As incidências AP da coluna cervical e AP com a boca aberta da região atlanto-axial (ou transoral) também devem ser obtidas (Figura 8). Na ausência de alterações nestas incidências, deve-se decidir se são necessárias às incidências oblíquas ou incidências dinâmicas (em flexão e extensão). As incidências dinâmicas devem ser sempre realizadas sob a supervisão de um médico para evitar uma lesão ou aumento da extensão de uma lesão neurológica.

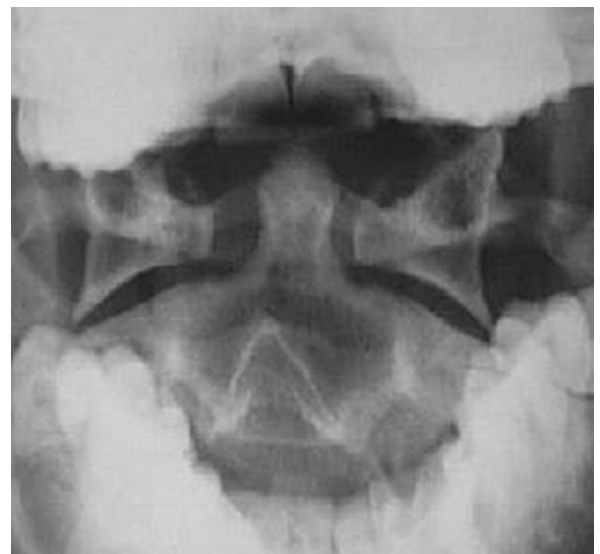

Figura 8. Incidência transoral. Radiografia simples da coluna - incidência transoral. Esta incidência é realizada para melhor visibilização do processo odontóide e suas relações com o atlas

O protocolo padrão de trauma raquimedular em nosso serviço é constituído das incidências AP, perfil, transoral e oblíquas.

Os sinais radiográficos associados à lesão da coluna cervical são:

- Aumento de partes moles retrofaríngea: maior que $10 \mathrm{~mm}$, na altura de C3 e C4 (Figura 9);

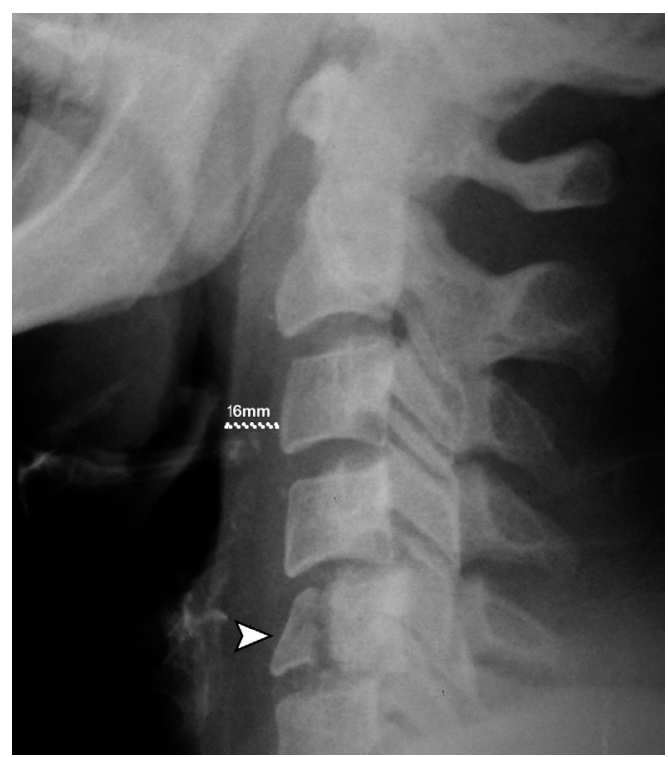

Figura 9. Aumento de partes moles retrofaríngea. Radiografia em perfil da coluna cervical mostra aumento de partes moles retrofaríngea, na altura de C3 e C4 (16 mm, para um normal de até $10 \mathrm{~mm}$ ). Presença de fratura completa do corpo vertebral de C5 (cabeça de seta) 
Rodrigues MB. Diagnóstico por imagem no trauma raquimedular - princípios gerais.

- Desalinhamento: melhor apreciado na incidência em perfil, onde 4 linhas convexas são formadas (Figura 10). A quebra da continuidade destas linhas, especialmente das 3 primeiras indica desalinhamento. É normal, no entanto, observar uma leve anterolistese de C3 sobre C4 em crianças (fisiológico). O alinhamento no plano frontal também deve ser observado, especialmente as paredes laterais e os processos espinhosos;

- Diminuição da altura do espaço discal: devido a um trauma no disco intervertebral;

- Aumento da distância entre os processos espinhosos;

- Variações na altura dos corpos vertebrais: associados geralmente a fraturas em cunha.

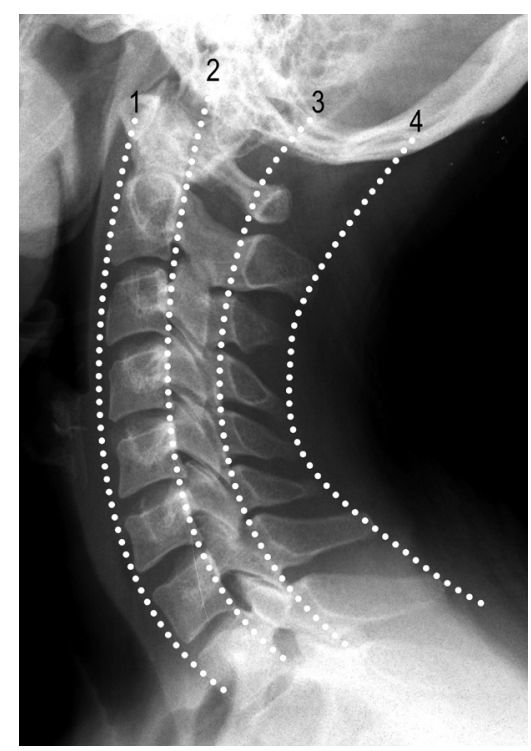

Figura 10. Alinhamento da coluna cervical. Radiografia da coluna cervical demonstrando as linhas convexas da coluna cervical. 1- Linha formada pela junção das margens anteriores de todos os corpos vertebrais. 2- Linha formada pela junção dos muros posteriores de todas as vértebras. 3-Linha formada pela junção das margens anteriores dos processos espinhosos / lâminas. 4- Junção das porções posteriores dos processos espinhosos

As radiografias simples podem não visibilizar as fraturas em $20 \%$ a $57 \%$ dos casos $^{9-11}$. Uma das limitações do RX é a impossibilidade de visibilizar a transição cérvico-torácica em diversas situações. A presença de tubos traqueais e peças dentárias também podem dificultar esta análise, especialmente na região atlanto-axial.

\section{Tomografia computadorizada}

A tomografia computadorizada (TC) é um excelente método adjuvante na avaliação do trauma raquimedular. Alguns estudos advogam o uso rotineiro da TC nesta avaliação ${ }^{12,13}$. Deve ser realizada em pacientes com lesão neurológica estabelecida ou naqueles com suspeita de lesão instável ao RX. Tem a vantagem de poder ser realizada com a imobilização ou tração cervical. Também é indicada nos pacientes politraumatizados graves que necessitem de uma rápida avaliação por imagem.

\section{Ressonância magnética}

A ressonância magnética $(\mathrm{RM})$ é indicada em pacientes com déficit neurológico parcial ou progressivo após o trauma, assim como em pacientes com instabilidade mecânica secundária a lesão ligamentar ou do disco intervertebral. Sua principal função é detectar compressão da medula espinhal por osso, disco ou hematoma para decidir se será necessária uma cirurgia descompressiva. Demonstra a herniação discal aguda pós-traumática, alterações na medula espinhal e lesões ligamentares (Figuras 11 e 12). 0 paciente politraumatizado grave pode ser impedido de realizar a RM, devido às suas condições clínicas e a impossibilidade de alocação dos sistemas de suporte a vida no ambiente de RM. A indicação ideal para RM é o paciente com déficit neurológico, sem alterações no RX ou TC e que não necessite de suporte à vida.

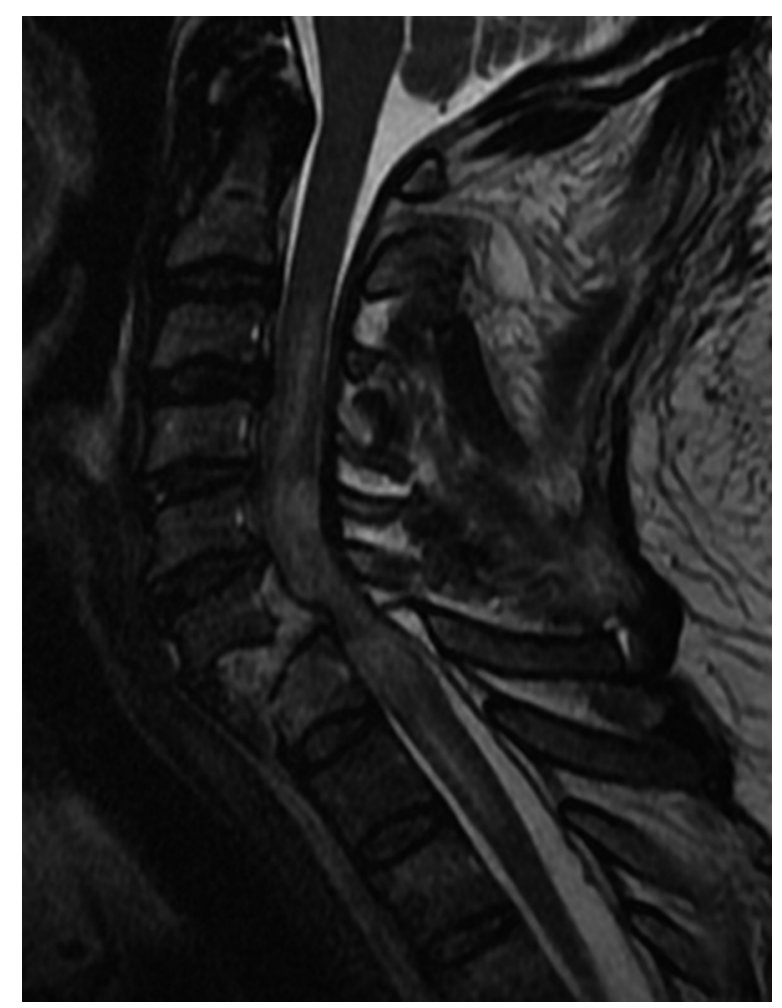

Figura 11. Mielopatia secundária a fratura vertebral. Ressonância magnética - imagem sagital da coluna cervical ponderada em T2. Fratura do corpo vertebral de C6, com deslocamento anterior e lesão da medula espinhal, que apresenta hiperssinal estendendose de C3 até D2. Paciente apresentava-se tetraplégico 


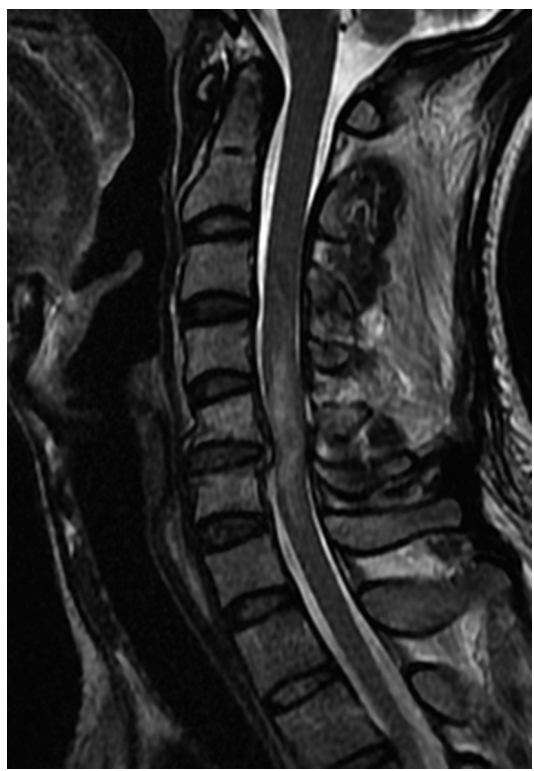

Figura 12. Hérnia discal aguda pós-traumática. Ressonância magnética - imagem sagital da coluna cervical ponderada em T2. Hérnia discal aguda de C5-C6, comprimindo a medula espinhal, que apresenta hiperssinal estendendo-se de $\mathrm{C} 4$ até $\mathrm{C} 7$

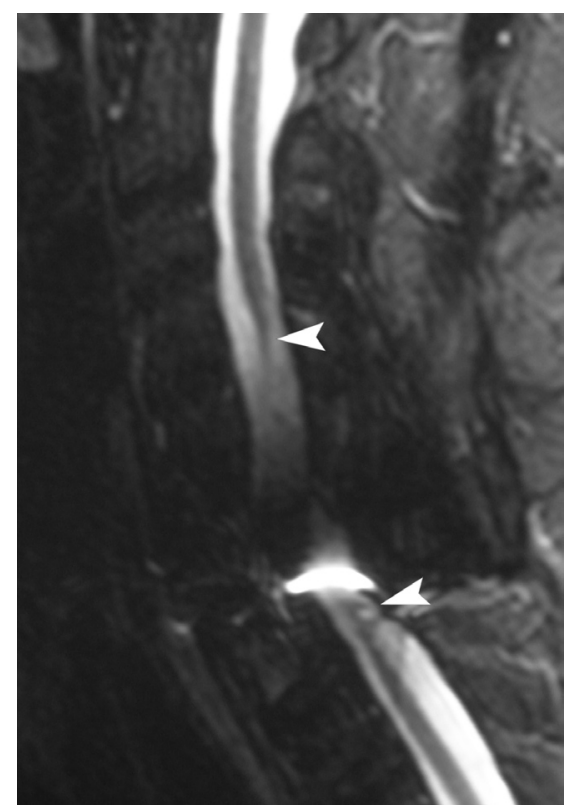

Figura 14. Seringomielia secundária a trauma raquimedular. Ressonância magnética - imagem sagital da coluna cervical ponderada em T2. Trauma raquimedular há 2 anos, com cirurgia prévia, observando-se cavidade seringomiélica na medula espinha (cabeça de seta), estendendo-se de C4 a C6

\section{FRATURAS ESPECÍFICAS}

\section{Fratura de Jefferson}

Caracterizada pelas fraturas bilaterais dos arcos anterior e posterior do atlas (C1) e produzida por uma força de compressão axial do crânio em
Outra aplicação da RM é no acompanhamento crônico de um trauma raquimedular, demonstrando atrofia medular e seringomielia (Figuras 13 e 14).

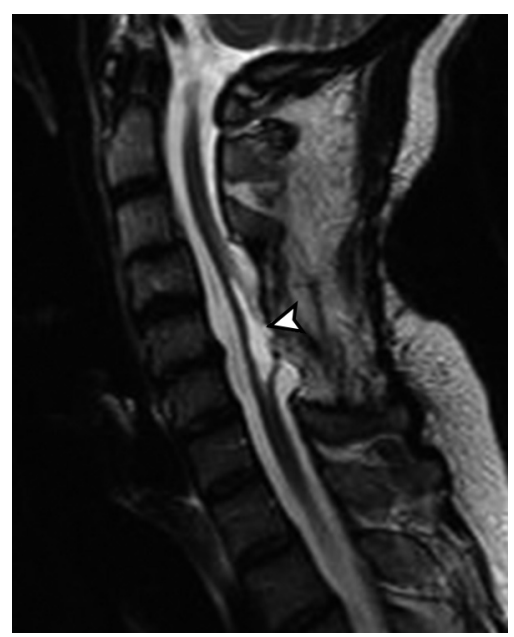

Figura 13. Transecção da medula espinhal. Ressonância magnética - imagem sagital da coluna cervical ponderada na sequência STIR (Short tau inversion recovery). Trauma raquimedular há 1 ano com instrumentação metálica em C6-C7-D1. Observe a transecção crônica e atrofia da medula espinhal com separação entre os cotos (cabeças de setas)

direção aos côndilos occipitais e coluna, ocorrendo principalmente em acidentes automobilísticos (Figura 15). É considerada estável quando o ligamento transverso não se rompe e existe afastamento lateral menor de $7 \mathrm{~mm}$ entre as massas laterais. A fratura instável ocorre quando existe lesão do ligamento transverso e afastamento maior que $7 \mathrm{~mm}$. Clinicamente, o paciente apresenta dor no pescoço e cefaléia occipital unilateral.

\section{Fratura do processo odontóide}

Ocasionada principalmente por lesões em hiperflexão do pescoço. A classificação mais aceita leva em conta a estabilidade da fratura ${ }^{14}$ (Figuras 16 a 18):

Tipo I: fratura na extremidade cranial do odontóide - cerca de $4 \%$ das fraturas do odontóide - estável.

Tipo II: fratura na base do odontóide - cerca de $66 \%$ das fraturas do odontóide - geralmente instável com alta de taxa de pseudoartrose (até $50 \%$ ).

Tipo III: fratura na base do odontóide, estendendo-se até o corpo de C2 - cerca de 30\% das fraturas - geralmente instável. 

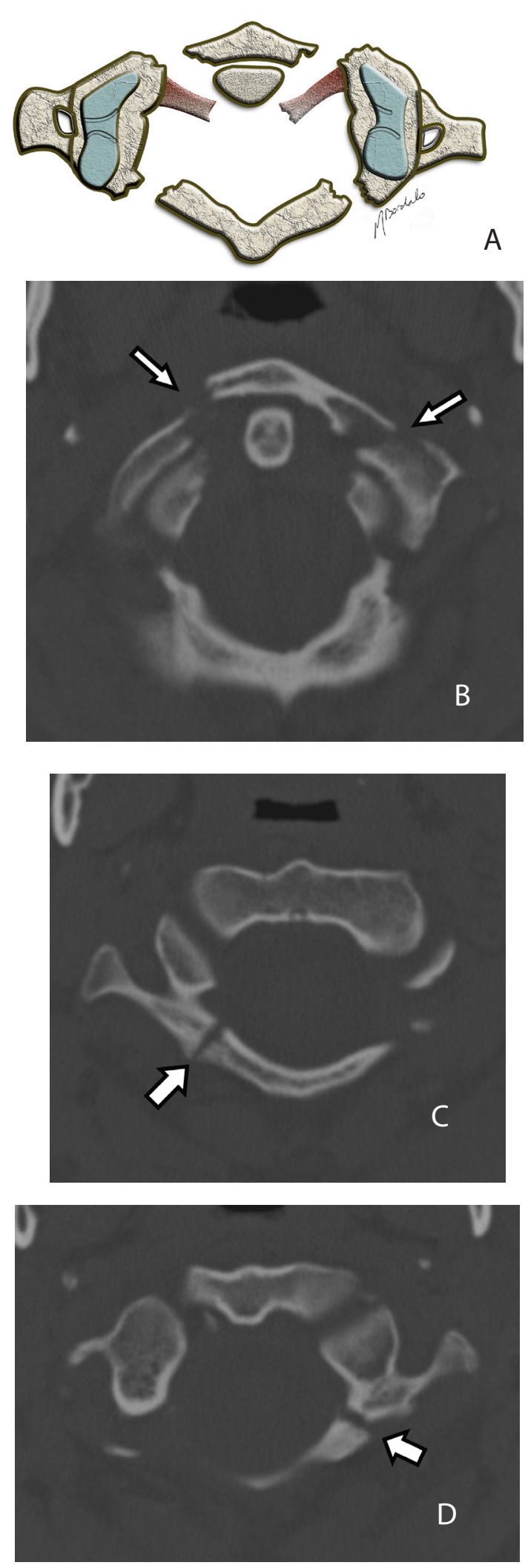

Figura 15. Fratura de Jefferson. (A) Esquema demonstra fratura dos arcos anterior e posterior de C1. (B a D) Imagens axiais de TC do atlas demonstram as fratura completas dos arcos anterior e posterior de C1 (setas)

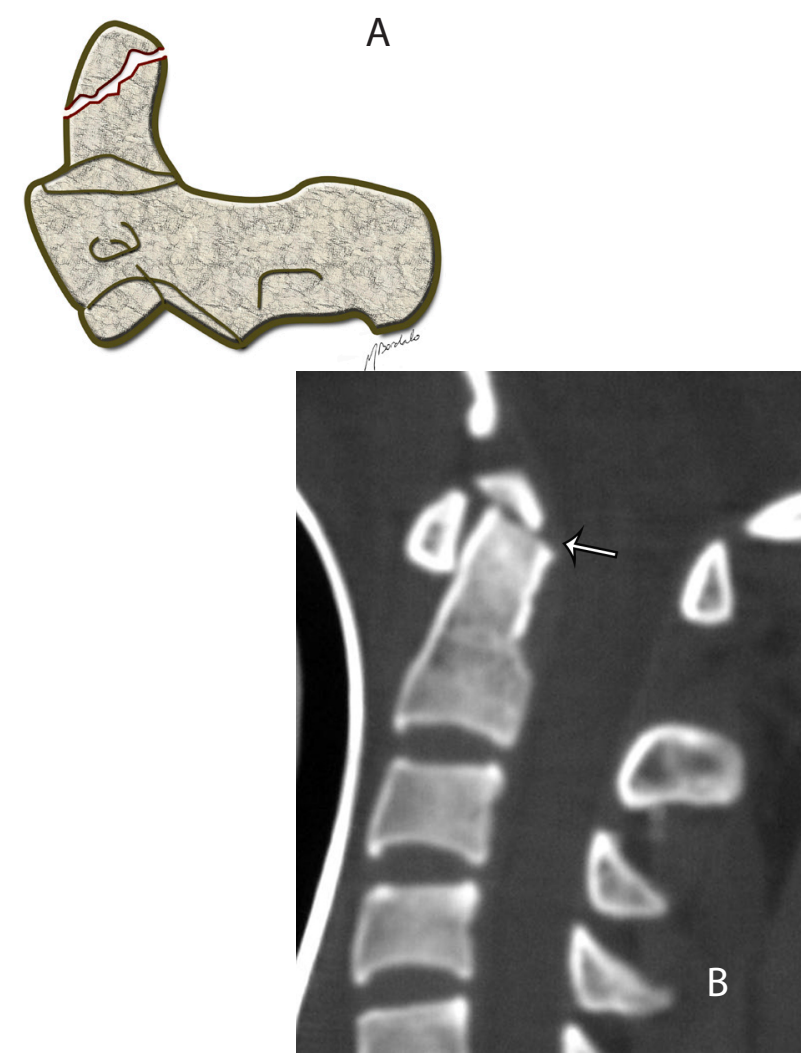

Figura 16. Fratura do Odontóide tipo I. (A) Esquema demonstra fratura tipo I do odontóide, com linha de fratura na extremidade proximal do odontóide. (B) Reformatação sagital de TC da coluna cervical - fratura da ponta do odontóide (seta)

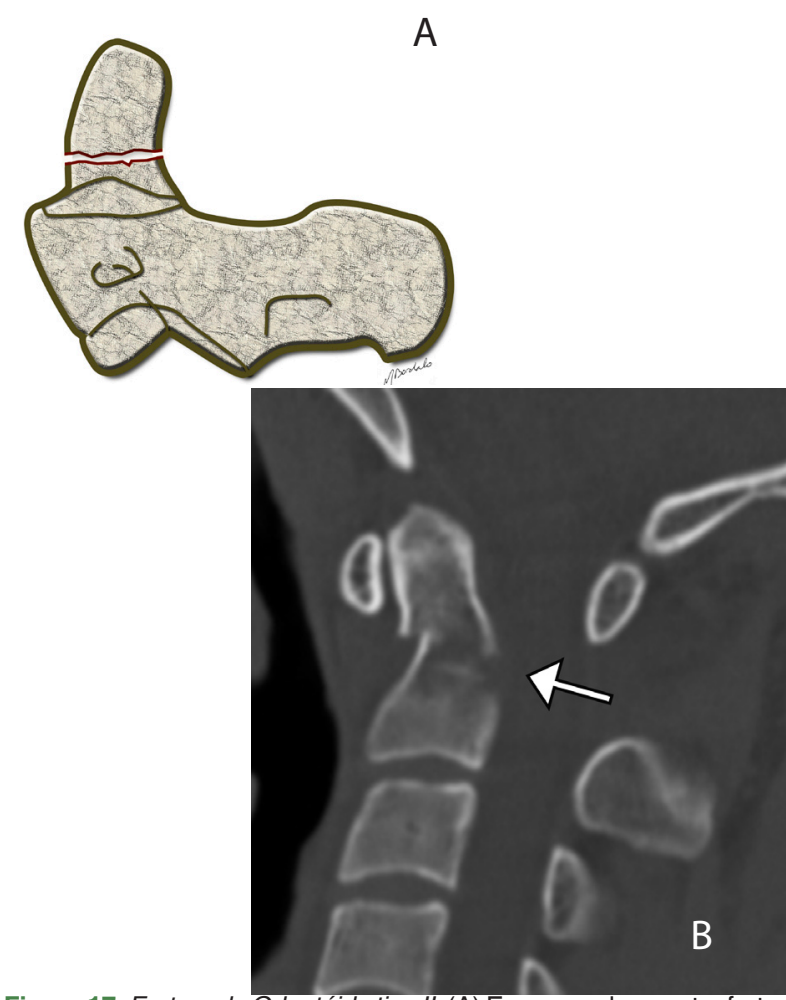

Figura 17. Fratura do Odontóide tipo II. (A) Esquema demonstra fratura tipo II do odontóide, com linha de fratura na base do odontóide. (B) Reformatação sagital de TC da coluna cervical - fratura da base do processo odontóide, sem extensão para o corpo vertebral (seta) 


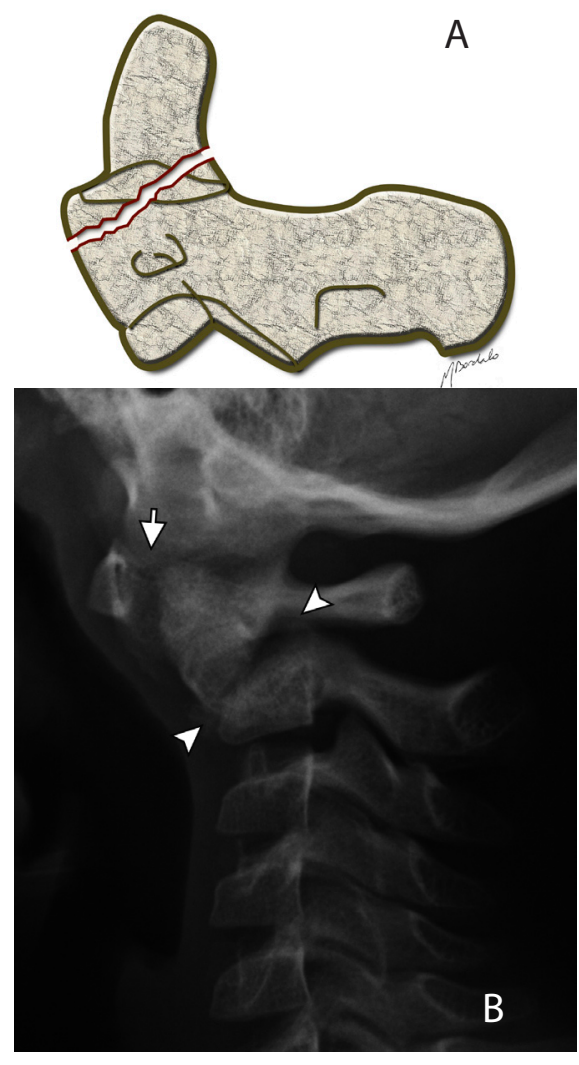

Figura 18. Fratura do Odontóide tipo III. (A) Esquema demonstra fratura tipo III do odontóide, com linha de fratura na base do odontóide, estendendo-se até o corpo vertebral. (B) Radiografia em perfil da coluna cervical - fratura da base do processo odontóide, com extensão para o corpo vertebral (cabeças de seta). Há um conseqüente deslocamento e "tilt" do processo odontóide com dissociação atlanto-axial (seta)

\section{A}
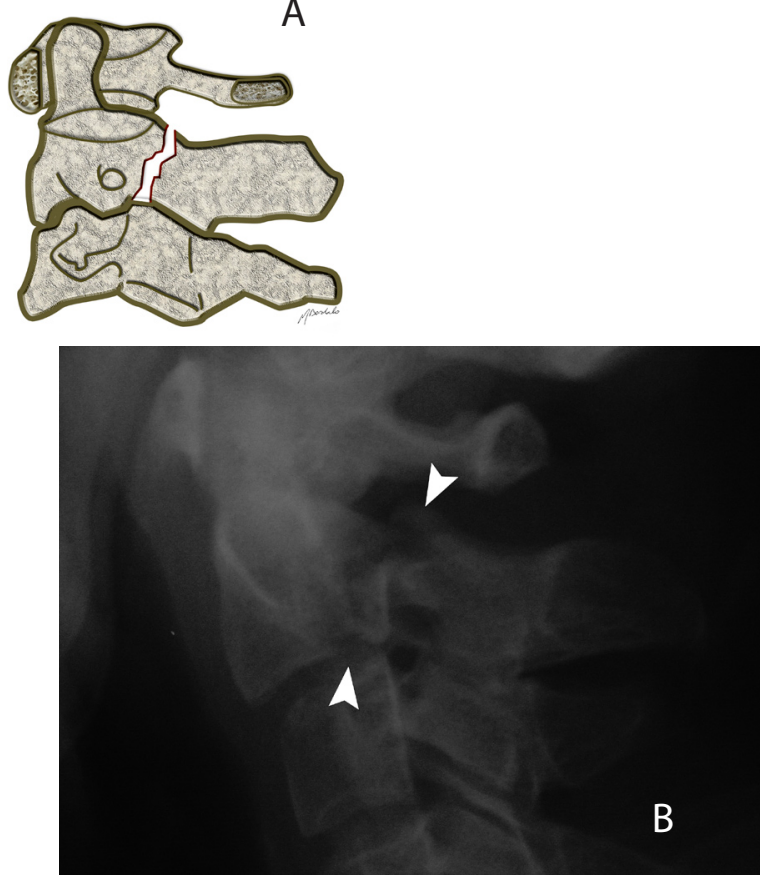

Figura 19. Fratura do Enforcado. (A) Esquema demonstra fratura completa oblíqua do pedículo de C2. (B) Radiografia em perfil da coluna cervical - fratura oblíqua completa do pedículo de C2, estendendose até o corpo vertebral póstero-inferior (cabeças de setas). Há um consequente deslocamento anterior de $\mathrm{C} 2$

\section{Fratura do enforcado}

O mecanismo associado às execuções por enforcamento foi descrito em 1912, sendo a hiperextensão e deslocamento do pescoço ${ }^{15}$. Este mecanismo leva a fratura do corpo de C2, acometendo os pedículos, levando a luxação anterior de C2 e laceração da medula espinhal. Conhecida, também, como espondilolistese traumática de C2. Nos tempos atuais, a principal causa destas fraturas é o acidente automobilístico no qual a face bate no volante ou no painel com conseqüente hiperextensão da cabeça.

Nas incidências laterais, observa-se uma fratura oblíqua, anteriormente às facetas inferiores, estendendo-se da porção póstero-superior à porção ântero-inferior do pedículo. Como conseqüência, ocorre uma subluxação/luxação de C2 sobre C3 (Figura 19). Raramente, a fratura é unilateral.

\section{Fratura em lágrima}

Fratura extremamente grave e instável ${ }^{16}$, causada por um mecanismo em hiperflexão do pescoço. Caracteriza-se pela fratura dos elementos posteriores com deslocamento posterior do corpo vertebral e consequente laceração da medula espinhal. Também ocorre lesão do ligamento longitudinal anterior com avulsão óssea do corpo vertebral, formando um fragmento triangular, em forma de lágrima, deslocado anteriormente e inferiormente (Figura 20).
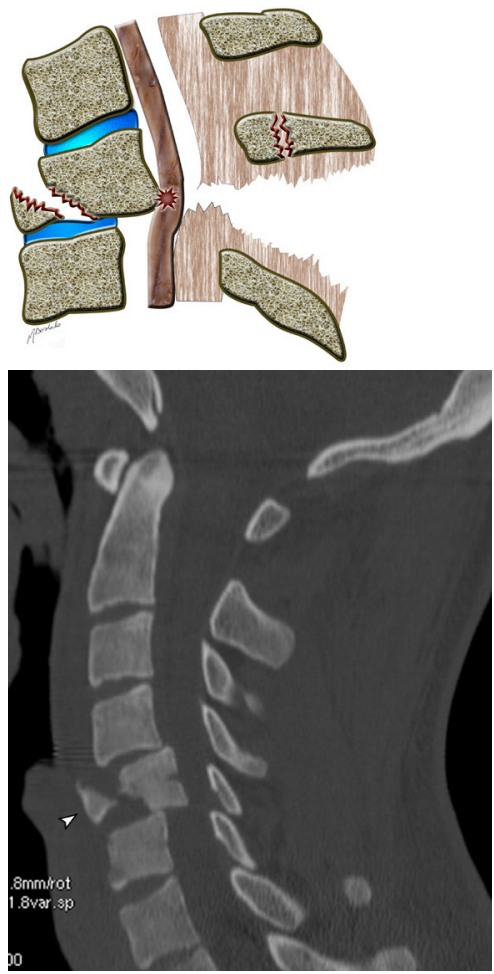

Figura 20. Fratura em Lágrima. (A) Esquema demonstra fratura em lágrima acometendo as colunas anterior, media e posterior, lesões ligamentares anteriores e posteriores com deslocamentos ósseos e conseqüente lesão da medula espinhal. (B) Reformatação sagital de TC da coluna cervical fratura da porção anterior C5, com fragmento triangular (cabeça de seta) e deslocamento posterior deste corpo vertebral 
Rodrigues MB. Diagnóstico por imagem no trauma raquimedular - princípios gerais.

O diagnóstico diferencial é a fratura em lágrima por extensão, que é uma lesão estável e cujo fragmento triangular apresenta o mesmo aspecto em relação a fratura em lágrima clássica (Figuras 2 e 21).
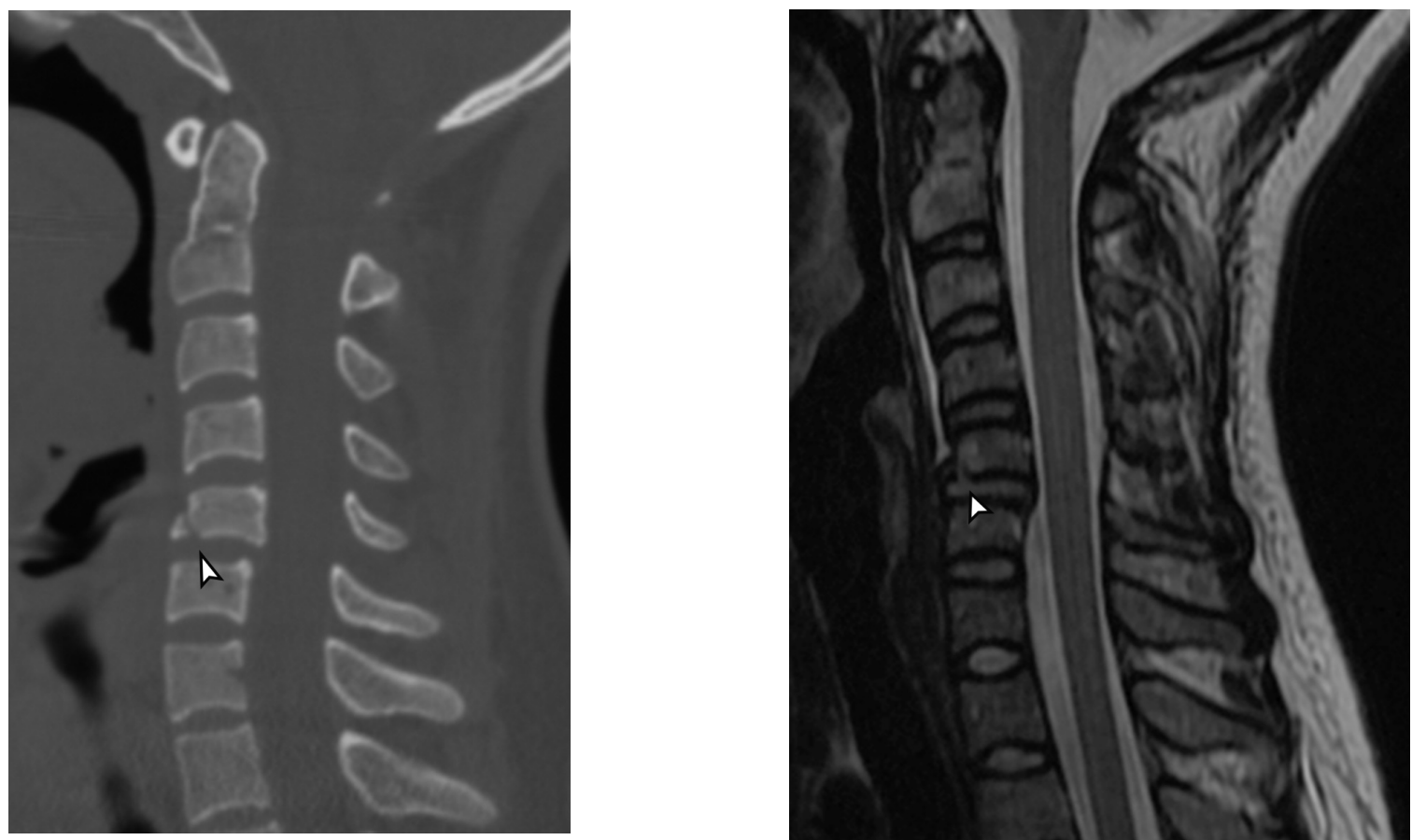

Figura 21. Fratura em Lágrima por extensão. (A) Reformatação sagital de TC da coluna cervical e (B)Imagem sagital de RM da coluna cervical ponderada em T2. Fratura da porção ântero-inferior do corpo verterbal de C5 com pequeno fragmento ósseo triangular (cabeça de seta). Esta fratura acomete apenas a coluna anterior sendo, portanto, uma fratura estável, ao contrário da clássica fratura em lágrima que acomete as 3 colunas e é instável

\section{Fratura do cavador de barro}

Fratura completa do processo espinhoso de $\mathrm{C} 6$ ou de $\mathrm{C} 7$, secundário a um mecanismo de hiperflexão aguda do pescoço, como as que ocorrem nos cavadores (Figura 22). No início do século, esta fratura era muito comum nos mineiros de barro, recebendo o nome de fratura do cavador de barro.

Trata-se de uma lesão estável, pois o complexo ligamentar anterior está intacto.

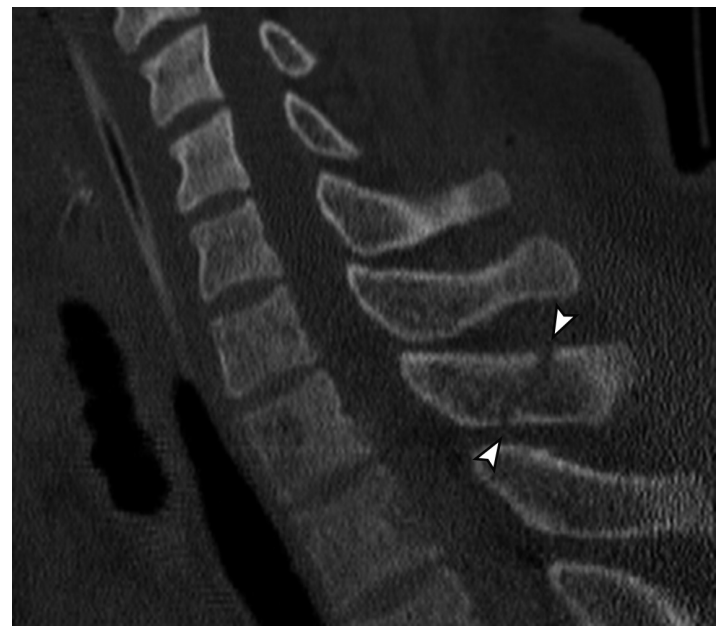

Figura 22. Fratura do Cavador de Barro. Reformatação sagital de TC da coluna cervical demonstra fratura completa do processo espinhoso de C7 (cabeças de setas)

\section{Fratura com facetas presas}

Lesão secundária a um mecanismo de flexão e rotação do pescoço levando a rotura do complexo ligamentar posterior e da cápsula articular da interapofisária com conseqüente subluxação posterior da faceta superior e conseqüente encarceramento com a faceta inferior da vértebra superior. Pode ser unilateral (estável) ou bilateral (instável), sendo neste último caso, bastante associada a lesão da medula espinhal (Figura 23).

\section{CONCLUSÃO}

O conhecimento dos mecanismos fisiopatológicos no trauma raquimedular é importante para o entendimento das características das diversas lesões. Os métodos por imagem são essenciais no seu diagnóstico e estadiamento, devendo-se, no entanto, sempre ser correlacionados com o quadro clínico para adequada valorização dos achados por imagem e conseqüente conduta terapêutica. 

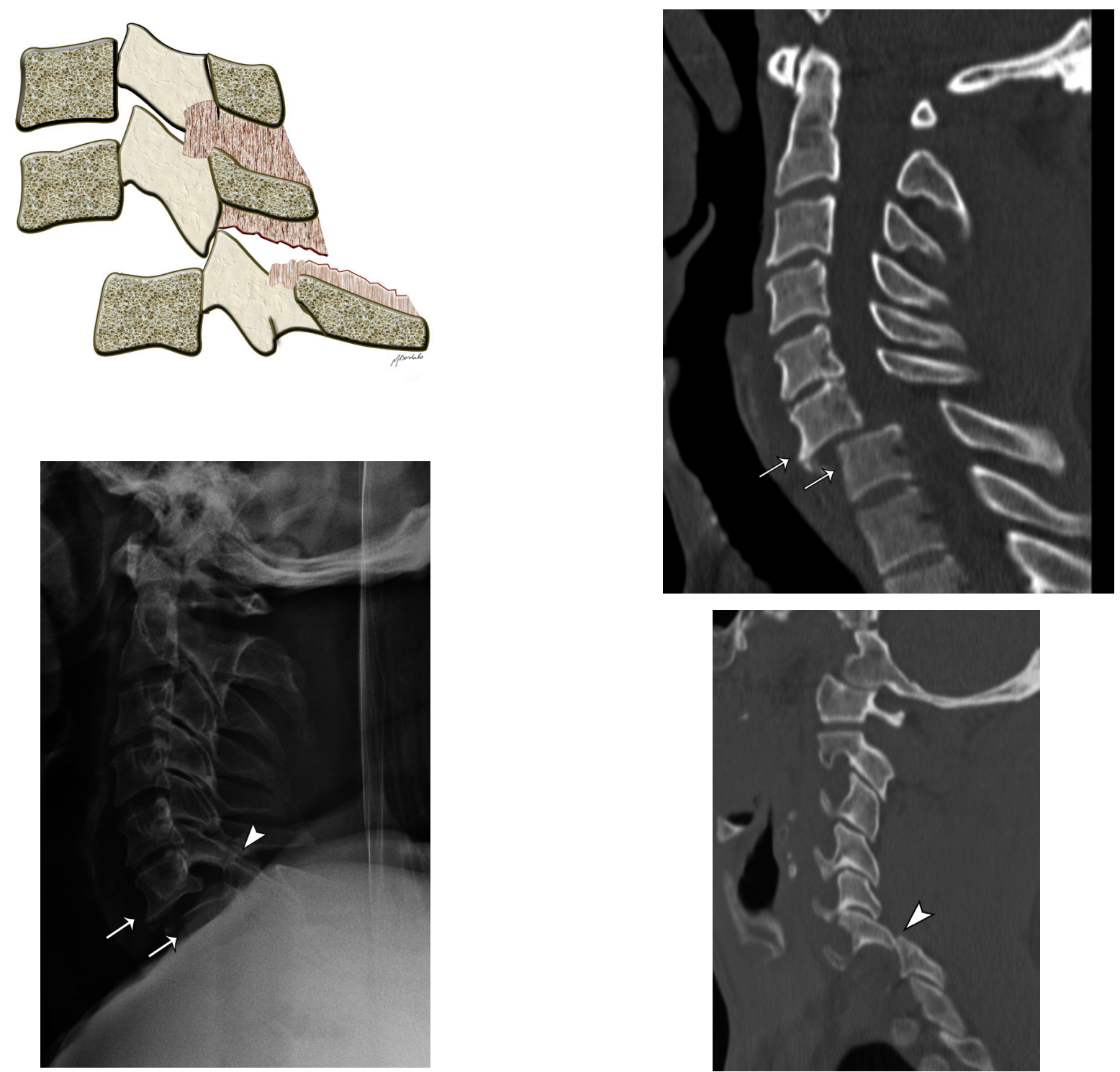

Figura 23. Facetas Presas. (A) Esquema demonstra deslocamento anterior de corpo vertebral com lesão ligamentar posterior e encarceramento das facetas apofisárias. A faceta superior da vértebra inferior desloca-se posteriormente em relação a faceta inferior da vértebra superior. (B) Radiografia em perfil da coluna cervical. Ântero-listese grau III de C6 sobre C7 (setas) com aprisionamento das facetas de C6 e C7 (cabeça de seta). (C e D) Reformatações sagitais de TC da coluna cervical demonstram a listese C6-C7(setas em C) e o deslocamento posterior da faceta superior de $\mathrm{C} 7$ em relação a faceta inferior de C6 (cabeça de seta em D)

\section{REFERÊNCIAS}

1 Jefferson G. Discussion on spinal Injuries. Proc B Soc Med. 1927-28;21:625.

2 Rogers L. Radiology of skeletal trauma. 3rd ed. New York: Churchill Livingstone; 2002.

3 Riggins RS, Kraus JF. The risk of neurologic damage with fractures of the vertebrae. J Trauma. 1977;17:12633.

4 Castellano V, Bocconi FL. Injuries of the cervical spine with spinal cord involvement (myelic fractures): statistical considerations. Bull Hosp Joint Dis. 1970;31:18894.
5 Del Bigio MR; Johnson GE. Clinical presentation of spinal cord concussion. Spine (Phila Pa). 1989;14:3740.

6 Schneider RC, Cherry G, Pantek H. The syndrome of acute central cervical spinal cord injury; with special reference to the mechanisms involved in hyperextension injuries of cervical spine. J Neurosurg. 1954;11:546-77. doi:10.3171/jns.1954.11.6.0546.

7 Denis $F$. The three column spine and its significance in the classification of acute thoracolumbar spinal injuries. Spine (Phila Pa). 1983;8:817-31. 
Rodrigues MB. Diagnóstico por imagem no trauma raquimedular - princípios gerais.

8 Denis F. Spinal instability as defined by the threecolumn spine concept in acute spinal trauma. Clin Orthop Relat Res. 1984:65-76.

9 Woodring $\mathrm{JH}$, Lee $\mathrm{C}$. Limitations of cervical radiography in the evaluation of acute cervical trauma. J Trauma. 1993;34:32-9.

10 Nunez DB Jr, Zuluaga A, Fuentes-Bernardo DA, Rivas LA, Becerra JL. Cervical spine trauma: how much more do we learn by routinely using helical CT? Radiographics. 1996;16:1307-18; discussion 1318-21.

11 Acheson MB, Livingston RR, Richardson ML, Stimac GK. High-resolution CT scanning in the evaluation of cervical spine fractures: comparison with plain film examinations. AJR Am J Roentgenol. 1987;148:117985.

12 Nunez D Jr. Value of complete cervical helical computed tomographic scanning in identifying cervical spine injury in the unevaluable blunt trauma patient with multiple injuries: a prospective study. J Trauma. 2000;48:988-89.

13 Blackmore CC, Ramsey SD, Mann FA, Deyo RA. Cervical spine screening with CT in trauma patients: a cost-effectiveness analysis. Radiology. 1999;212:11725.

14 Anderson LD, D'Alonzo RT. Fractures of the odontoid process of the axis. J Bone Joint Surg Am. 1974;56:1663-74.

15 Schneider RC, Livingston KE, Cave AJ, Hamilton G. Hangman's fracture of the cervical spine. J Neurosurg. 1965;22:141-54. doi:10.3171/jns.1965.22.2.0141.

16 Kahn EA, Schneider RC. Chronic neurological sequelae of acute trauma to the spine and spinal cord. I. The significance of the acute-flexion or tear-drop fracturedislocation of the cervical spine. J Bone Joint Surg Am. 1956;38-A:985-97. 